\title{
Biophysical modelling to investigate the effects of climate change on marine population dispersal and connectivity
}

\author{
Christophe Lett $^{\mathrm{a},{ }^{*}}$, Sakina-Dorothée Ayata ${ }^{\mathrm{b}, \mathrm{c}}$, Martin Huret ${ }^{\mathrm{d}}$ and Jean-Olivier Irisson ${ }^{\mathrm{e}, 1}$
}

\begin{abstract}
${ }^{a}$ UMI IRD 209 and UPMC UMMISCO, Centre de Recherche Halieutique Méditerranéenne et Tropicale, Avenue Jean Monnet, BP 171, 34203 Sète Cedex, France

${ }^{\mathrm{b}}$ Université Pierre et Marie Curie - Paris 06, UMR 7144, Station Biologique de Roscoff, BP 74, 29682 Roscoff Cedex, France

${ }^{\mathrm{c}}$ CNRS, UMR 7144, Station Biologique de Roscoff, BP 74, 29682 Roscoff Cedex, France

${ }^{d}$ EMH, Centre Ifremer de Nantes, Rue de l'lle d'Yeu, BP 21105, 44311 Nantes Cedex 3, France

e Centre de Biologie et d'Écologie Tropicale et Méditerranéenne, UMR 5244 CNRS-EPHE-UPVD, 52 av Paul Alduy, 66860 Perpignan Cedex, France

${ }^{1}$ Present address: UPMC Univ. Paris 06 - CNRS, UMR 7093, LOV, Observatoire océanographique, F-06234, Villefranche/mer, France.
\end{abstract}

\author{
* Corresponding author : Christophe Lett, Tel.: +33 4995732 55; fax: +33 4995732 95, email \\ address : christophe.lett@ird.fr \\ sakina.ayata@normalesup.org (S.-D. Ayata), martin.huret@ifremer.fr (M. Huret), \\ irisson@normalesup.org (J.-O. Irisson).
}

\begin{abstract}
:
Climate may act on the dispersal and connectivity of marine populations through changes in the oceanic circulation and temperature, and by modifying species' prey and predator distributions. As dispersal and connectivity remain difficult to assess in situ, a first step in studying the effects of climate change can be achieved using biophysical models. To date, only a few biophysical models have been used for this purpose. Here we review these studies and also include results from other recent modelling efforts. We show that increased sea temperature, a major change expected under climate warming, may impact dispersal and connectivity patterns via changes in reproductive phenology (e.g., shift in the spawning season), transport (e.g., reduced pelagic larval duration under faster development rates), mortality (e.g., changes in the exposure to lethal temperatures), and behaviour (e.g., increased larval swimming speed). Projected changes in circulation are also shown to have large effects on the simulated dispersal and connectivity patterns. Although these biophysical modelling studies are useful preliminary approaches to project the potential effects of climate change, we highlight their current limitations and discuss the way forward, in particular the need for adequate coupled hydrodynamic-biogeochemical simulations using atmospheric forcing from realistic climate change scenarios.
\end{abstract}




\section{Introduction}

Pelagic dispersal of larvae is a crucial process in the life cycle of most marine populations as it enables exchange of individuals, or connectivity, between distant sites. Consequently, the interest in marine population dispersal and connectivity is broad and worldwide. A special issue on "Marine population connectivity" (Cowen et al., 2007) and a theme section on "Larval connectivity, resilience and the future of coral reefs" (Jones et al., 2009a) are among the recent signs of this interest. Despite recent progress (Levin, 2006; Jones et al., 2009b), larval dispersal and connectivity remain difficult to assess in situ. It is indeed challenging to observe directly the dispersion of a multitude of small individuals diluted in vast expanses of oceanic waters. Assessing the potential effects of climate change on dispersal and connectivity in these populations is even harder. Harley et al. (2006) synthesized the potential effects of climate change on marine populations. They showed the life cycle of a generic marine organism with larval and adult stages (green in Figure 1) and the effects of climate change acting directly on this population (yellow in Figure 1), or indirectly via interactions with other species (blue in Figure 1). Some of these effects are expected to affect larval dispersal.

\section{HERE FIGURE 1}


Potential effects of climate change on marine populations include changes in current circulation and water temperature (Harley et al., 2006). Modification in circulation could modify dispersal pathways. The importance of external atmospheric forcing (temperature but also wind, heat fluxes, or freshwater input) on turbulence, stratification, and thermohaline- and wind-induced circulation gives insights on how regional circulation and mesoscale features may be affected by climate change. Climate change may also downscale from global perturbations (e.g., the reduction of Atlantic Meridional Overturning Circulation, Stouffer et al., 2006) to regional scale. Thus, larval transport patterns may be directly and strongly influenced by climate change.

Water temperature increase may also act on several key parameters of larval life. There is evidence of shifts in abundance and distribution of marine fish (Perry et al., 2005; Rijnsdorp et al., 2009) and larvae (Hsieh et al., 2009) that are believed to be largely driven by changes in temperature (Pörtner and Farrell, 2008). A direct effect of the increase of water temperature could be reduced exposure to lethal temperatures and, as a consequence, increased survival. A recent meta-analysis (O'Connor et al., 2007) demonstrated a negative relationship between temperature and planktonic larval durations (PLDs) for a wide range of marine species. Reduced PLDs induced by temperature increases could lead to substantial modifications of dispersal and connectivity patterns. The differences between the development and behavioural abilities of tropical fish larvae versus temperate ones also give a sense of what the consequences of a temperature increase could be for the ontogeny of larvae in temperate ecosystems; most tropical species develop faster and reach higher swimming speeds and endurance than temperate ones (Leis, 2006). Finally, warmer temperatures could also induce changes in reproductive phenology, especially by inducing earlier spawning (Olive et al, 1990; Edwards and Richardson, 2004). 
To summarise, an increase in water temperature may impact marine population dispersal and connectivity patterns via changes in spawning phenology (earlier spawning of adults), larval transport (shorter pelagic larval durations), larval mortality (reduced exposure to lethal temperatures and shorter larval life) and behaviour (increased larval swimming speed). Changes in ocean circulation and in exposure to lethal temperatures are examples of factors acting at the population level (represented by the "transport processes" yellow box in Harley et al. (2006); arrow number 1 in Figure 1). Earlier spawning of adults on the one hand, and shorter pelagic larval duration and increased larval swimming speed on the other, are examples of factors acting at the individual level (the "physiological, morphological, and behavioral effects" yellow box in Harley et al. (2006); arrows number 2 and 3 respectively in Figure 1).

A first step in the assessment of the effects of climate change on marine population dispersal and connectivity can be achieved using biophysical models. Biophysical models of marine population dispersal have been extensively developed in the last 20 years to simulate the fate of the pelagic life stages of marine organisms (reviews by Werner et al., 2001; Runge et al., 2005; Miller, 2007; Werner et al., 2007; Cowen and Sponaugle, 2009; Lett et al., 2009; Metaxas and Saunders, 2009). The processes represented in these biophysical models include transport, growth, behaviour, mortality, and settlement of eggs and larvae in a virtual marine environment. This environment usually consists of dynamic three-dimensional fields of physical (velocity, temperature, etc.) and biological (phytoplankton and zooplankton concentrations, etc.) variables provided by coupled hydrodynamic-biogeochemical models. A few biophysical models have been explicitly used to 
investigate the potential effects of climate change on connectivity. Here we review this information (Vikebø et al., 2007; Heath et al., 2008; Irisson, 2008; Lett et al., 2009; Munday et al., 2009) and other recent modelling efforts (Ayata et al., this issue; Huret et al., this issue). We then highlight the limitations of the current modelling approaches and suggest the best way forward. 


\section{Biophysical models and climate change}

Vikebø et al. (2007) used a biophysical model to simulate transport and growth of larvae and pelagic juveniles of cod (Gadus morhua) in the Nordic Seas under normal and anomalous environmental conditions. Anomalous conditions were obtained by increasing the river runoff to the seas by a factor of three in their hydrodynamic model. This scenario led to dramatic changes in circulation and temperature in the hydrodynamic simulations, which had important consequences for the dispersal and growth of early life stages of cod in the biophysical model. In particular, transport patterns shifted significantly and individual growth was reduced. Although Vikebø et al. (2007) recognized that they used an extreme scenario, an increase in river runoff is consistent with the expected effects of climate change in the region.

Heath et al. (2008) used a biophysical model for the same species (cod, Gadus morhua) in the North Sea. In their model, temperature along the drift trajectory was used to simulate growth of larvae and faster growing larvae experienced higher survival rates. Larvae were tracked until they attained a given length at which time they settled. Over the 1980-1999 period, Heath et al. (2008) obtained significant increases of the probability of cod eggs spawned in two specific areas to be retained in their natal area, and attributed this trend to climate change. More precisely, this result is likely due to an increase in sea temperature in these areas over time, as warmer waters led to faster growth in the model and therefore to reduced mortality and earlier settlement. Both effects contributed to increased retention. 
Munday et al. (2009) used the biophysical model from Paris et al. (2007) to investigate the effects of shorter PLDs on dispersal and connectivity patterns of a coral reef fish (Thalassoma bifasciatum). A $20 \%$ reduction in PLD led to fewer larvae dispersing over long distances and changed the overall recruitment pattern, increasing self-recruitment dramatically. As a result, local connectivity increased, but only in areas of sufficiently high reef density whereas connections between reefs were weaker or lost in areas of low reef density. Therefore, Munday et al. (2009) concluded that, in fragmented habitats like coral reef ecosystems, the precise effect of reduced PLD on connectivity patterns likely depends on the distribution of suitable habitats for settlement.

Lett et al. (2009) used the evolutionary biophysical model developed by Mullon et al. (2002) to explore how environmental constraints could affect the spatial and temporal spawning patterns of small pelagic fish in the southern Benguela upwelling system. They imposed simple constraints to drifting ichthyoplankton for multiple generations and assumed philopatry: successful individuals reproduce at the same time and place as their parents. This allowed the seasonal and spatial patterns of spawning to emerge from a selective process driven by environmental conditions. When they used the constraint of staying close to the shelf in waters warmer than $15^{\circ} \mathrm{C}$ throughout the drift period, the spawning patterns that emerged were in broad agreement with those observed for anchovy (Engraulis encrasicolus) and sardine (Sardinops sagax) in the southern Benguela. When they changed the temperature-related mortality from $15^{\circ} \mathrm{C}$ to $14^{\circ} \mathrm{C}$ or $16^{\circ} \mathrm{C}$, the selected spawning patterns changed significantly, both spatially and temporally. Lett et 
al. (2009) interpreted these changes within the context of climate change, with a cooler $\left(14^{\circ} \mathrm{C}\right)$ threshold mimicking warmer waters and a warmer $\left(16^{\circ} \mathrm{C}\right)$ threshold mimicking cooler waters. Lett et al. (2009) obtained contrasting results for these two assumptions; earlier westward spawning was predicted for the warming scenario, later eastward spawning was predicted for the cooling scenario. There has been a slight warming trend in sea surface water in the southern Benguela during the last decade (Demarcq, 2009). Regional climate projections currently available suggest an average increase of near-surface temperature by $2.5^{\circ} \mathrm{C}$ over the Benguela region between 1980-1999 and 2080-2099 (Christensen et al., 2007). However, Wang et al. (2010) reported that climate projections showed a particularly high degree of uncertainty in coastal upwelling regions. In addition, the water that is upwelled at the coast comes from greater depths and might not display the warming trends predicted for surface waters. An intensification of upwelling-favourable winds is also expected under climate change (Bakun, 1990) and was observed in the southern Benguela for the last decade (Demarcq, 2009). Therefore, considering either warming or cooling of southern Benguela coastal waters as a result of climate change are two plausible assumptions.

Ayata et al. (this issue) simulated larval dispersal and connectivity for a generic invertebrate species inhabiting a coastal, fragmented habitat in the Bay of Biscay and in the western English Channel. From their results, the consequences of two possible effects of an increase in sea surface temperature on dispersal and connectivity can be discussed: (1) shorter PLD and (2) earlier spawning. For a maximum temperature increase of $5.3^{\circ} \mathrm{C}$ over Europe (Christensen et al., 2007), such as from 9 to $14.3^{\circ} \mathrm{C}$, the PLD would decrease from 4 to 2 weeks following the universal relationship proposed by O'Connor et al. (2007) between PLD and water temperature. Ayata et 
al. (this issue) compared dispersal kernels and connectivity matrices obtained for these two PLD values among 16 populations and demonstrated a significant impact of PLD on the dispersal kernels. Whatever the spawning month and the spawning population, shorter PLD resulted in shorter mean dispersal distances. On average, a decrease of 50\% in PLD (from 4 to 2 weeks) caused a decrease of $45 \%$ in mean dispersal distance (Figure 2A). Regarding connectivity, such a decrease in PLD increased retention and larval exchange between neighbouring populations (local connectivity) but decreased exchanges between more distant populations (regional connectivity). Moreover, the connectivity size, defined as the total number of connections between all spawning populations, decreased by $30 \%$, indicating an overall loss of connectivity (Figure 2B). Ayata et al. (this issue) also simulated monthly spawning from February to August for 2001 to 2005 (35 dates). Whereas no year-to-year variations in dispersal kernels were observed, the date of spawning within each year had a significant influence on the variability of dispersal kernels, likely because of the strong seasonal patterns in the circulation of the Bay of Biscay. Larval transport occurred north-westwards from February to April and south-eastwards from May to August. These results suggested that, for the invertebrate populations of the Bay of Biscay, earlier spawning, in April instead of May, could cause reversed dispersal directions from SE to NW, hence favouring the connectivity to more northern populations (Ayata et al., this issue). Earlier spawning would also increase the connectivity, from $48 \pm 9$ (mean $\pm \mathrm{SD}$ ) connections for spawning occurring between May and August to $65 \pm 12$ connections for spawning occurring between February and April (for a PLD of 4 weeks).

\section{HERE FIGURE 2}


Another modelling study in the Bay of Biscay (Huret et al., this issue) investigated the effects of spawning date and PLD on anchovy (Engraulis encrasicolus) dispersal. The simulation covered the period 1996-2007. As in Ayata et al. (this issue) for the northern Bay of Biscay, Huret et al. (this issue) showed that in the southeastern bay the peak spawning season (May-June) of anchovy occurs just after a shift in coastal circulation from northward to southward. Earlier spawning due to a likely temperature increase would then cause a significant change in the dispersal pattern of anchovy early life stages, in particular for those spawned near the coast. Huret et al. (this issue) also evaluated the effect of the duration of the pelagic phase on several indices describing the dispersal kernel. A reduction of the PLD would have the average effect of linearly reducing the mean dispersal distance and the variance of the distribution around its mean position (inertia), as well as increasing the aggregation of larvae.

In addition to direct and indirect effects of temperature increase on development rates or phenology, we extended the study of Huret et al. (this issue) to investigate here the impact of other physical properties likely affected by climate change (stratification, turbulence and circulation) on anchovy larval dispersal in the Bay of Biscay. The modelling exercise consisted of separate perturbations of the atmospheric forcing of two contrasting years (2001 and 2002): (1) temperature, (2) wind, and (3) combined temperature and wind. We call these 'what if' climate change scenarios, in contrast to dynamic downscaling of projections from global circulation models. The perturbations are based on estimates from Christensen et al.'s (2007) regional projections, under IPCC projections for the end of the $21^{\text {st }}$ century. The first scenario considers 
an increase in air temperature by $3^{\circ} \mathrm{C}$, which is within the expected range of variation over Europe (2.2 to $5.3^{\circ} \mathrm{C}$; Christensen et al., 2007). The second scenario considers a wind increase of $30 \%$, well within the range of climatic variability. Such an increase in average and extreme wind speeds is expected over northern Europe, although with a relatively low degree of confidence (Christensen et al., 2007). The third scenario is a combination of both the temperature and wind increase. Perturbations are applied homogeneously in space and time over both simulated years. Table 1 shows that the air temperature increase (1) and combined (3) scenarios result in an average increase in sea surface temperature (SST) of $\sim 2.2^{\circ} \mathrm{C}$ over the Bay of Biscay, whereas in the wind increase scenario (2) SST decreases by $0.58^{\circ} \mathrm{C}$. The stratification is strengthened in scenario 1 and weakened for scenarios 2 and 3 with the wind increase.

\section{HERE TABLE 1}

Under these modified oceanographic conditions, the average distance transported, the inertia and the positive area of the dispersal kernel are strongly affected, whereas the direction of drift is not significantly modified (Figure 3, Table 2). Note that, despite opposite effects of increased air temperature and wind on surface temperature and stratification (Table 1), their effects on our descriptors are both positive (scenarios 1 and 2) and are cumulative when acting together (scenario 3). Comparing the variations of these descriptors between scenarios (Table 2) highlights the greater impact of temperature (scenarios 1 and 3) on the mean distance transported, and of wind (scenarios 2 and 3) on dispersion. Stronger stratification caused by increased temperatures concentrates particles in the surface layers and they are thus more affected by surface wind or 
thermohaline circulation, whereas stronger winds may increase turbulence and dispersal of particles in a deeper mixed layer, eventually increasing dispersal of particles in the horizontal dimension.

HERE FIGURE 3

HERE TABLE 2

Irisson (2008) studied the effect of fast development of swimming abilities in warm waters on local retention of fish populations, using a modelling framework that allowed explicit simulations of larval behaviour throughout the larval phase (Irisson et al. 2004). These results are published here for the first time. In brief, larvae were advected by currents but could also swim, up to a maximum speed that increased as larvae grew. Larvae selected trajectories that allowed them to self-recruit while spending as little energy on swimming as possible. This left more energy allocatable to growth and indirectly affected survival, because large or fast-growing larvae usually survive better (Cowan and Houde, 1992; Sponaugle and Grorud-Colvert, 2006). Simulations were carried out for generic, weakly swimming, temperate fish larvae (PLD of $27 \mathrm{~d}$, maximum swimming speed at settlement of $5 \mathrm{~cm} \mathrm{~s}^{-1}$ ) in a stratified flow (averaging $20 \mathrm{~cm} \mathrm{~s}^{-1}$ at the surface and $12 \mathrm{~cm} \mathrm{~s}^{-1}$ at depth) around two idealized coastal environments (an island and a promontory). Although weak, the swimming abilities of larvae allowed them to dive down, 
towards slower currents, at the beginning of the larval phase and to stay within eddies in the lee of the feature later on, hence facilitating their retention (Figure 4).

\section{HERE FIGURE 4}

Provided food is sufficient, an increase in water temperature accelerates ontogeny, particularly of swimming abilities, and shortens the PLD (O'Connor et al., 2007), which both affect trajectories. The simulation of a $2^{\circ} \mathrm{C}$ increase in water temperature showed that larvae were able to swim downward earlier and to be retained in the lees of the topographic features in greater numbers (Irisson, 2008). The percentage of successfully recruiting larvae increased (Table 3). The rate of self-recruitment was estimated as recruitment percentage $\times$ PLD $\times$ daily mortality rate $(0.27$, Houde and Zastrow (1993), adjusted upwards after the $2^{\circ} \mathrm{C}$ increase according to Houde (1974) and Houde (1989)). The combination of shorter PLD and higher recruitment percentage resulted in a threefold increase in self-recruitment rate in the climate change scenarios (Table 3). These simulations highlighted the influence of oriented swimming on retention, even at slow speeds (2 $\mathrm{cm} \mathrm{s}^{-1}$ on average here), and suggested that the warming of oceanic waters could result in greater retention through faster development. 


\section{Discussion}

The hydrodynamic simulations reported here represent the most important features of the marine environments in the different systems under study that populations currently face. These environments were used in biophysical models depicting dispersal of early life stages to test the influence of a few variables that are expected to be particularly sensitive to climate change (spawning season, pelagic larval duration, exposure to hot and cold water temperatures, and swimming speed). Our results, combined with previous studies, show that a decrease in pelagic larval durations caused by an increase in water temperature (within the range currently expected under climate change; Christensen et al., 2007; Meehl et al., 2007) would increase selfrecruitment, suppress long distance dispersal and, overall, reduce average dispersal distance. However, these effects are not universal. Indeed, in the Bay of Biscay, the mean dispersal distance for a small pelagic fish would increase because of climate-induced changes in water circulation. Furthermore, the overall effect of reduced PLD on connectivity probably depends on the distribution of settlement habitats. We also showed that early spawning could completely reverse the direction of dispersal, as occurred in the model of the Bay of Biscay, for example. Similarly, changes in river runoff could dramatically affect circulation patterns and dispersal routes. Finally, a reduction in PLD could combine with fast development of swimming abilities in warm waters and could lead to an increase in larval retention, and therefore self-recruitment.

These conclusions need to be taken with caution however, because when testing the effects of climate change on a particular variable we implicitly assumed that all others remained unchanged 
and that there were no interactions between these variables. However, such interactions could play an important role in altering dispersal and connectivity. As an example, if phenological changes, such as early spawning, occur in reponse to an increase in temperature, the new environment encountered by larvae (e.g. different prey and predator distributions) could have both a positive or a negative effect on larval mortality. The modification of spawning dates can also influence connectivity patterns in any number of ways depending on its interaction with circulation (more retention vs. enhanced long distance dispersal and anything in between). Observations of egg distributions over decades (e.g., Bellier et al., 2007) also suggest that spawning locations, the starting point of our dispersal models, could be modified by adult populations in response to a changing environment. To get better insights into the consequences of climate change, biophysical models should integrate the influence of various environmental variables (temperature, circulation, etc.) on the different processes occurring during the pelagic phase (larval transport, growth, behaviour, mortality, and settlement). There is also a need to better understand and consider the potential acclimation and adaptation of individuals to changing environmental conditions in biophysical models (Franklin and Seebacher, 2009).

The simulations we described did not include state-of-the-art regional climate change scenarios, such as those provided by the Intergovernmental Panel on Climate Change (Christensen et al., 2007). The parameterizations used to describe climate change (shortening of PLD, warming of water, increase of wind speed, etc.) were within the range of variations provided by these scenarios and they are a preliminary approach to assess the response of regional connectivity to climate variability. However they lack the spatial and temporal dimensions of this variability. For example, many of our examples rely on an homogeneous increase in sea water temperature, a 
simplifying assumption that is clearly wrong. Indeed, from satellite sea surface temperature (SST) data in the North Atlantic between 1985 and 2005, Gómez-Gesteira et al. (2008) projected a mean annual increase in the coastal SST of $3.5^{\circ} \mathrm{C}$ per century at latitudes close to $48^{\circ} \mathrm{N}$, but with a maximum increase, in spring, of $5.1^{\circ} \mathrm{C}$ along the French Atlantic coast and of $4.4^{\circ} \mathrm{C}$ along the Cantabrian coast.

Besides this type of 'experimental' use of models, where only one variable is changed at a time, another approach could be to use contrasted present conditions and compare connectivity between years, regions, etc. Such work was done in the Caribbean, to compare the response to climate change of regions differing in habitat fragmentation (Paris et al., 2008; Munday et al., 2009) and in the Bay of Biscay (Ayata et al., this issue) to predict shifts in drift direction depending on currents observed during different periods of the year. Basing a model on observed past or present data and iterating those in time allows retention of the complex interactions among variables while still studying the long term effects of different conditions.

Our approach constitutes a first step in the investigation of the effects of climate change on marine population dispersal and connectivity, in the absence of adequate hydrodynamic simulations for climate change scenarios in the regions under study. Atmosphere-ocean general circulation models using climate change scenarios exist at the global scale (Russell et al., 2006; Meehl et al., 2007). Downscaling at regional scale is still rare (Auad et al., 2006; Christensen et al., 2007) and reveals many uncertainties (Meier et al., 2006; Ådlandsvik, 2008). Pierce et al. (2009) pointed out the importance of downscaling from an ensemble of global models to reduce 
the internal variability and errors contained in individual models. Interest in such methodological developments is growing as they allow regional projections of the dynamics of marine populations (e.g., Hollowed et al., 2009) and because this is the scale at which biophysical models of dispersal operate. An even greater challenge would be the projection of the dynamics of the whole ecosystem, starting with its biogeochemistry (Denman et al., 2007), which would be needed if growth is included in larval biophysical models. Indeed, larvae that grow quickly in warm waters have a fast metabolism and need to eat more (Houde, 1974). Since a large part of the mortality in temperate waters is believed to be caused by the lack of food, accurate modelling of prey fields is necessary. Methods for the downscaling of global climate projections at the regional lower trophic level are developing (Solidoro et al., 2010) and coupled hydrodynamicbiogeochemical simulations forced by downscaled regional projections are becoming available (Neumann, 2010). They should help investigations of the influence of climate change on plankton dynamics and therefore on feeding opportunities for the early life stages of other marine populations.

Finally, even for models operating in present-day conditions, there still is a significant gap between our abilities to simulate larval dispersal with biophysical models and to experimentally measure connectivity. Considerable progress has been achieved on both sides. The possibility of estimating connectivity patterns through parentage analysis (Jones et al., 2005; Planes et al., 2009) and mass marking (Almany et al., 2007; Becker et al., 2007; Thorrold et al., 2007) is promising, although these methods may be difficult to apply for some systems or species. Comparing real (observed) and virtual (modelled) drifters is also a useful way to validate the physical transport predicted by biophysical models (Edwards et al., 2006; Fach and Klinck, 2006; 
Chérubin and Richardson, 2007). A challenge for the future is to integrate all these advances (Levin, 2006; Jones et al., 2009b; Metaxas and Saunders, 2009).

We have focused our study on the potential effects of climate change on marine population dispersal and connectivity. Biophysical models of marine population dispersal are expected to provide useful information, particularly if, as explained above, they are used within multidisciplinary studies integrating other complementary approaches. Of course, climate-related changes in dispersal and connectivity are not the only explanations for shifts currently observed in the distribution of marine fishes (Perry et al., 2005; Rijnsdorp et al., 2009) and larvae (Hsieh et al., 2009). Other processes, in particular trophic interactions (the blue part in Figure 1), are also likely to play a crucial role. For example, we showed that changes in spawning phenology impacted dispersal and connectivity patterns of a given population, but these changes could also lead to trophic mismatches (Edwards and Richardson, 2004; Cury et al., 2008). We recommend using a suite of models, comprising larval dispersal models, models describing the spatial dynamics of both larval and adult stages (e.g., Andrews et al., 2006) and trophic models (e.g., Travers et al., 2007), in combination with experimental assessments, to investigate ecological responses of marine systems to climate change at the individual, population, and community levels. 


\section{Acknowledgments}

The authors thank the organisers of the GLOBEC-France symposium, and particularly F.

Carlotti, for giving them the opportunity to meet, discuss, and propose the present contribution.

S.-D. Ayata was supported by a PhD grant from the French Ministry of National Education and Research and by the French national project EC2CO (Ecosphère Continentale et Côtière). M. Huret received financial support for this work from european project RECLAIM (FP6 - Contract 044133). J.-O. Irisson work is part of a PhD grant from the French Ministry of National Education and Research. He thanks S. Planes and C. Paris, his advisor and co-advisor, for their help and support. The authors would also like to thank C.L. Moloney and two anonymous reviewers for their comments. 


\section{References}

Ådlandsvik, B., 2008. Marine downscaling of a future climate scenario for the North Sea. Tellus A 60 (3), 451-458.

Almany, G.R., Berumen, M.L., Thorrold, S.R., Planes, S., Jones, G.P., 2007. Local replenishment of coral reef fish populations in a marine reserve. Science 316 (5825), 742-744.

Andrews, J.M., Gurney, W.S.C., Heath, M.R., Gallego, A., O'Brien, C.M., Darby, C., Tyldesley, G., 2006. Modelling the spatial demography of Atlantic cod (Gadus morhua) on the European continental shelf. Canadian Journal of Fisheries and Aquatic Sciences 63 (5), 1027-1048.

Auad, G., Miller, A., Di Lorenzo, E., 2006. Long-term forecast of oceanic conditions off California and their biological implications. Journal of Geophysical Research-Oceans 111, C09008, doi:10.1029/2005JC003219. 
Ayata, S.-D., Lazure, P., Thiébaut, E., submitted. How does the connectivity between populations mediate range limits of marine invertebrates? A case study in the NE Atlantic. Progress in Oceanography this issue.

Bakun, A., 1990. Global climate change and intensification of coastal ocean upwelling. Science 247 (4939), 198-201.

Becker, B.J., Levin, L.A., Fodrie, F.J., McMillan, P.A., 2007. Complex larval connectivity patterns among marine invertebrate populations. Proceedings of the National Academy of Sciences of the United States of America 104 (9), 3267-3272.

Bellier, E., Planque, B., Petitgas, P., 2007. Historical fluctuations in spawning location of anchovy (Engraulis encrasicolus) and sardine (Sardina pilchardus) in the Bay of Biscay during 1967-73 and 2000-2004. Fisheries Oceanography 16 (1), 1-15.

Chérubin, L.M., Richardson, P.L., 2007. Caribbean current variability and the influence of the Amazon and Orinoco freshwater plumes. Deep-Sea Research Part I-Oceanographic Research Papers 54 (9), 1451-1473. 
Christensen, J.H. et al., 2007. Regional climate projections. In: S. Solomon et al. (Eds.), Climate change 2007: the physical science basis. Contribution of working group I to the fourth assessment report of the Intergovernmental Panel on Climate Change. Cambridge University Press, Cambridge, UK, 296p.

Cowan, Jr,J.H., Houde, E.D., 1992. Size-dependent predation on marine fish larvae by ctenophores, scyphomedusae, and planktivorous fish. Fisheries Oceanography 1 (2), 113-126.

Cowen, R.K., Gawarkiewicz, G., Pineda, J., Thorrold, S.R., Werner, F.E., 2007. Population connectivity in marine systems: an overview. Oceanography 20 (3), 14-21.

Cowen, R.K., Sponaugle, S., 2009. Larval dispersal and marine population connectivity. Annual Review of Marine Science 1, 443-466.

Cury, P.M. Shin, Y.-J., Planque, B., Durant, J.M., Fromentin, J.-M., Kramer-Schadt, S., Stenseth, N.C., Travers, M., Grimm, V., 2008. Ecosystem oceanography for global change in fisheries. Trends in Ecology \& Evolution 23 (6), 338-346. 
Demarcq, H., 2009. Trends in primary production, sea surface temperature and wind in upwelling systems (1998-2007). Progress in Oceanography 83 (1-4), 376-385.

Denman, K.L. et al., 2007. Couplings between changes in the climate system and biogeochemistry. In: Solomon, S., Qin, D., Manning, M., Chen, Z., Marquis, M., Averyt, K.B., Tignor, M., Miller, H.L. (Eds.). Climate Change 2007: The physical science basis. Contribution of working group I to the fourth assessment report of the Intergovernmental Panel on Climate Change. Cambridge University Press, Cambridge, UK and New York, USA.

Edwards, M., Richardson, A.J., 2004. Impact of climate change on marine pelagic phenology and trophic mismatch. Nature 430(7002), 881-884.

Edwards, K.P., Hare, J.A., Werner, F.E., Blanton, B.O., 2006. Lagrangian circulation on the southeast US continental shelf: implications for larval dispersal and retention. Continental Shelf Research 26(12-13), 1375-1394.

Fach, B.A., Klinck, J.M., 2006. Transport of Antarctic krill (Euphausia superba) across the Scotia Sea. Part I: Circulation and particle tracking simulations. Deep-Sea Research Part IOceanographic Research Papers 53(6), 987-1010. 
Franklin, C.E., Seebacher, F., 2009. Adapting to climate change. Science 323(5916), 876-876.

Gómez-Gesteira, M., deCastro, M., Alvarez, I., Gómez-Gesteira, J.L., 2008. Coastal sea surface temperature warming trend along the continental part of the Atlantic Arc (1985-2005). Journal of Geophysical Research 113, C04010, doi:10.1029/2007JC004315.

Harley, C.D.G. Hughes, A.R., Hultgren, K.M., Miner, B.G., Sorte, C.J.B., Thornber, C.S., Rodriguez, L.F., Tomanek, L., Williams, S.L., 2006. The impacts of climate change in coastal marine systems. Ecology Letters 9(2), 228-241.

Heath, M.R., Kunzlik, P.A., Gallego, A., Holmes, S., Wright, P.J., 2008. A model of metapopulation dynamics for North Sea and West of Scotland cod - The dynamic consequences of natal fidelity. Fisheries Research 93(1-2), 92-116.

Hollowed, A.B., Bond, N.A., Wilderbuer, T.K., Stockhausen, W.T., Teresa A'mar, Z., Beamish, R.J., Overland, J.E., Schirripa, M.J., 2009. A framework for modelling fish and shellfish responses to future climate change. ICES Journal of Marine Science 66, 1584-1594. 
Houde, E.D., 1974. Effects of temperature and delayed feeding on growth and survival of larvae of three species of subtropical marine fishes. Marine Biology 26(3), 271-285.

Houde, E.D., 1989. Comparative growth, mortality, and energetics of marine fish larvae: Temperature and implied latitudinal effects. Fisheries Bulletin 87(3), 471-495.

Houde, E.D., Zastrow, C.E., 1993. Ecosystem- and taxon-specific dynamic and energetics properties of larval fish assemblages. Bulletin of Marine Science 53(2), 290-335.

Hsieh, C.-H., Kim, H.J., William, W., Di Lorenzo, E., Sugihara, G., 2009. Climate-driven changes in abundance and distribution of larvae of oceanic fishes in the southern California region. Global Change Biology, doi: 10.1111/j.1365-2486.2009.01875.x.

Huret, M., Petitgas, P., Woillez, M., submitted. Dispersal kernels and their drivers captured with a hydrodynamic model and spatial indices: a case study on anchovy (Engraulis encrasicolus) early life stages in the Bay of Biscay. Progress in Oceanography this issue. 
Irisson, J.-O., Levan, A., De Lara, M., Planes, S., 2004. Strategies and trajectories of coral reef fish larvae optimizing self-recruitment. Journal of Theoretical Biology 227, 205-218.

Irisson, J.-O., 2008. Behavioural approach to larval dispersal in marine systems. Ph.D. Thesis, Ecole doctorale de l'Ecole Pratique des Hautes Etudes.

Jones, G.P., Planes, S., Thorrold, S.R., 2005. Coral reef fish larvae settle close to home. Current Biology 15(14), 1314-1318.

Jones, G.P., Russ, G.R., Sale, P.F., Steneck, R.S., 2009a. Theme section on "Larval connectivity, resilience and the future of coral reefs". Coral Reefs 28(2), 303-305.

Jones, G.P. Almany, G.R., Russ, G.R., Sale, P.F., Steneck, R.S., van Oppen, M.J.H., Willis, B.L., 2009b. Larval retention and connectivity among populations of corals and reef fishes: history, advances and challenges. Coral Reefs 28(2), 307-325.

Leis, J.M., 2006. Are larvae of demersal fishes plankton or nekton? Advances in Marine Biology $51,57-141$. 
Lett, C., Rose, K.A., Megrey, B., 2009. Biophysical models. In: Checkley, D.M., Alheit, J., Oozeki, Y., Roy, C. (Eds.). Climate change and small pelagic fish. Cambridge University Press, Cambridge, UK, pp. 88-111.

Levin, L.A., 2006. Recent progress in understanding larval dispersal: new directions and digressions. Integrative and Comparative Biology 46(3), 282-297.

Meehl, G.A. et al., 2007. Global climate projections. In: Solomon, S., Qin, D., Manning, M., Chen, Z., Marquis, M., Averyt, K.B., Tignor, M., Miller, H.L. (Eds.). Climate change 2007: the physical science basis. Contribution of working group I to the fourth assessment report of the Intergovernmental Panel on Climate Change. Cambridge University Press, Cambridge, UK.

Meier, H.E.M., Kjellström, E., Graham, L.P., 2006. Estimating uncertainties of projected Baltic Sea salinity in the late 21st century. Geophysical Research Letters 33, L15705, doi:10.1029/2006GL026488. 
Metaxas, A., Saunders, M., 2009. Quantifying the "bio-" components in biophysical models of larval transport in marine benthic invertebrates: advances and pitfalls. Biological Bulletin 216, 257-272.

Miller, T.J., 2007. Contribution of individual-based coupled physical-biological models to understanding recruitment in marine fish populations. Marine Ecology Progress Series 347, $127-$ 138.

Mullon, C, Cury, P, Penven, P., 2002. Evolutionary individual-based model for the recruitment of anchovy (Engraulis capensis) in the southern Benguela. Canadian Journal of Fisheries and Aquatic Sciences 59, 910-922.

Munday, P.L., Leis, J.M., Lough, J.M., Paris, C.B., Kingsford, M.J., Berumen, M.L., Lambrechts, J., 2009. Climate change and coral reef connectivity. Coral Reefs 28(2), 379-395.

Neumann, T., 2010. Climate-change effects on the Baltic Sea ecosystem: A model study. Journal of Marine Systems 81(3), 213-224. 
O'Connor, M.I., Bruno, J.F., Gaines, S.D., Halpern, B.S., Lester, S.E., Kinlan, B.P., Weiss, J.M., 2007. Temperature control of larval dispersal and the implications for marine ecology, evolution, and conservation. Proceedings of the National Academy of Sciences of the United States of America 104(4), 1266-1271.

Olive, P., Clark, S., Lawrence, A., 1990. Global warming and seasonal reproduction: perception and transduction of environmental information. Advances in Invertebrate Reproduction, 5, 265270.

Paris, C.B., Chérubin, L.M., Cowen, R.K., 2007. Surfing, spinning, or diving from reef to reef: effects on population connectivity. Marine Ecology Progress Series 347, 285-300.

Paris, C.B., Clement, A., Cowen, R.K., 2008. Influence of projected temperature changes in the Caribbean on the pelagic phase and population networks of a common reef fish. Abstract, session 071, Ocean Sciences Meeting, Orlando, USA.

Perry, A.L., Low, P.J., Ellis, J.R., Reynolds, J.D., 2005. Climate change and distribution shifts in marine fishes. Science 308(5730), 1912-1915. 
Pierce, D.W., Barnett, T.P., Santer, B.D., Gleckler, P.J., 2009. Selecting global climate models for regional climate change studies. Proceedings of the National Academy of Sciences of the United States of America 106(21), 8441-8446.

Planes, S., Jones, G.P., Thorrold, S.R., 2009. Larval dispersal connects fish populations in a network of marine protected areas. Proceedings of the National Academy of Sciences of the United States of America 106(14), 5693-5697.

Pörtner, H.O., Farrell, A.P., 2008. Physiology and climate change. Science 322(5902), 690-692.

Rijnsdorp, A.D., Peck, A.P., Engelhard, G.H., Möllman, C., Pinnegar, J.K., 2009. Resolving the effect of climate change on fish populations. ICES Journal of Marine Science 66, 1570-1583.

Runge, J.A., Frank, P.J.S., Gentleman, W.C., Megrey, B.A., Rose, K.A., Werner, F.E., Zakardjian, B., 2005. Diagnosis and prediction of variability in secondary production and fish recruitment processes: developments in physical-biological modelling. In: Robinson, A.R., Brink, K.H. (Eds.). The Sea, Vol. 13, The Global Coastal Ocean: Multiscale Interdisciplinary Processes. Harvard University Press, Cambridge, MA, pp. 413-473. 
Russell, J.L., Stouffer, R.J., Dixon, K.W., 2006. Intercomparison of the Southern Ocean circulations in IPCC coupled model control simulations. Journal of Climate 19(18), 4560-4575.

Solidoro, C., Cossarini, G., Libralato, S., Salon, S., 2010. Remarks on the redefinition of system boundaries and model parameterization for downscaling experiments. Progress in Oceanography 84(1-2), 134-137.

Sponaugle, S., Grorud-Colvert, K., 2006. Environmental variability, early life-history traits, and survival of new coral reef fish recruits. Integrative and Comparative Biology 46(5), 623-633.

Stouffer, R.J., Yin, J., Gregory, J.M., Dixon, K.W., Spelman, M.J.,Hurlin, W., Weaver, A.J.,Eby, M., Flato, G.M., Hasumi, H., Hu, A., Jungclaus, J.H., Kamenkovich, I.V., Levermann, A., Montoya, M., Murakami, S., Nawrath, S., Oka, A., Peltier, W.R., Robitaille, D.Y., Sokolov, A., Vettoretti, G., Weber, S.L., 2006. Investigating the causes of the response of the thermohaline circulation to past and future climate changes. Journal of Climate 19(8), 1365-1387.

Thorrold, S.R., Zacherl, D.C., Levin, L.A., 2007. Population connectivity and larval dispersal using geochemical signatures in calcified structures. Oceanography 20(3), 80-89. 
Travers, M., Shin, Y.J., Jennings, S., Cury, P., 2007. Towards end-to-end models for investigating the effects of climate and fishing in marine ecosystems. Progress in Oceanography 75(4), 751-770.

Vikebø, F.B., Sundby, S., Ådlandsvik, B., Otterå, O.H., 2007. Impacts of a reduced thermohaline circulation on transport and growth of larvae and pelagic juveniles of Arcto-Norwegian cod (Gadus morhua). Fisheries Oceanography 16(3), 216-228.

Wang, M., Overland, J.E., Bond, N.A., 2010. Climate projections for selected large marine ecosystems. Journal of Marine Systems 79(3-4), 258-266.

Werner, F.E., Cowen, R.K., Paris, C.B., 2007. Coupled biological and physical models: present capabilities and necessary developments for future studies of population connectivity. Oceanography 20(3), 54-69.

Werner, F.E., Quinlan, J.A., Lough, R.G., Lynch, D.R., 2001. Spatially-explicit individual based modeling of marine populations: a review of the advances in the 1990s. Sarsia 86(6), 411-421. 


\section{Figure legends}

Figure 1: Potential effects of climate change on a generic marine population (adapted from Harley et al. (2006). MUST ASK PERMISSION TO REPRODUCE). The life cycle of this generic organism is in green. The effects of climate change are in yellow (direct effects) and blue (indirect effects). The arrows in red highlight the effects more specifically investigated in this paper. Numbers are used in the text to refer to these arrows.

Figure 2: Consequence of a decrease in planktonic larval duration (PLD) from 4 to 2 weeks in (A) mean dispersal distance and (B) connectivity size for a generic invertebrate species in the fragmented habitat of the Bay of Biscay. Connectivity size is defined as the number of connections between all 16 spawning populations. Averages and standard deviations (error bars) were calculated for 35 spawning dates from February to August 2001 to 2005 and for 16 spawning populations (see Ayata et al., this issue, for details). A decrease of 50\% in the PLD from 4 to 2 weeks resulted in decreases of mean dispersal distance from $73 \pm 51 \mathrm{~km}$ to $40 \pm 29$ $\mathrm{km}($ mean $\pm \mathrm{SD})$ and of connectivity size from $55 \pm 13$ to $37 \pm 8$ connections.

Figure 3: Boxplots (medians are the thick lines, quartiles are the boxes, whiskers extend to the farthest points that are not outliers, i.e. that are within $3 / 2$ times the range between quartiles, and means are black bullets) of four dispersal kernel descriptors under the different climate change scenarios (Ref: reference, Temp: air temperature $+3^{\circ} \mathrm{C}$, Wind: wind $+30 \%$, Comb: combined 
temperature and wind increase). Within scenario variability is obtained from 14 different releases between the beginning of March and end of August in 2001 and 2002. Duration of the drift is 50 days. Distance is the distance between the centre of gravity of the particle distribution at their starting and final positions. Inertia and positive area both represent dispersion; inertia is the variance of the distribution at the end of the drift and positive area is the sum of model grid cells with positive concentrations of particles. It relates to dispersion at a smaller scale than inertia. Direction is the direction of the mean transport from east counterclockwise. See Huret et al. (this issue) for further details on the spatial descriptors of the dispersal kernel.

Figure 4: Simulated 3D trajectories (white curves with black outline) of larvae between 0 and 110 m-depth around a promontory. The current flows from the right to the left of the plot, as depicted by the arrow near the bottom. Larvae start near the promontory, swim deeper initially and then actively stay in the lee of the promontory. 


\section{Figures}

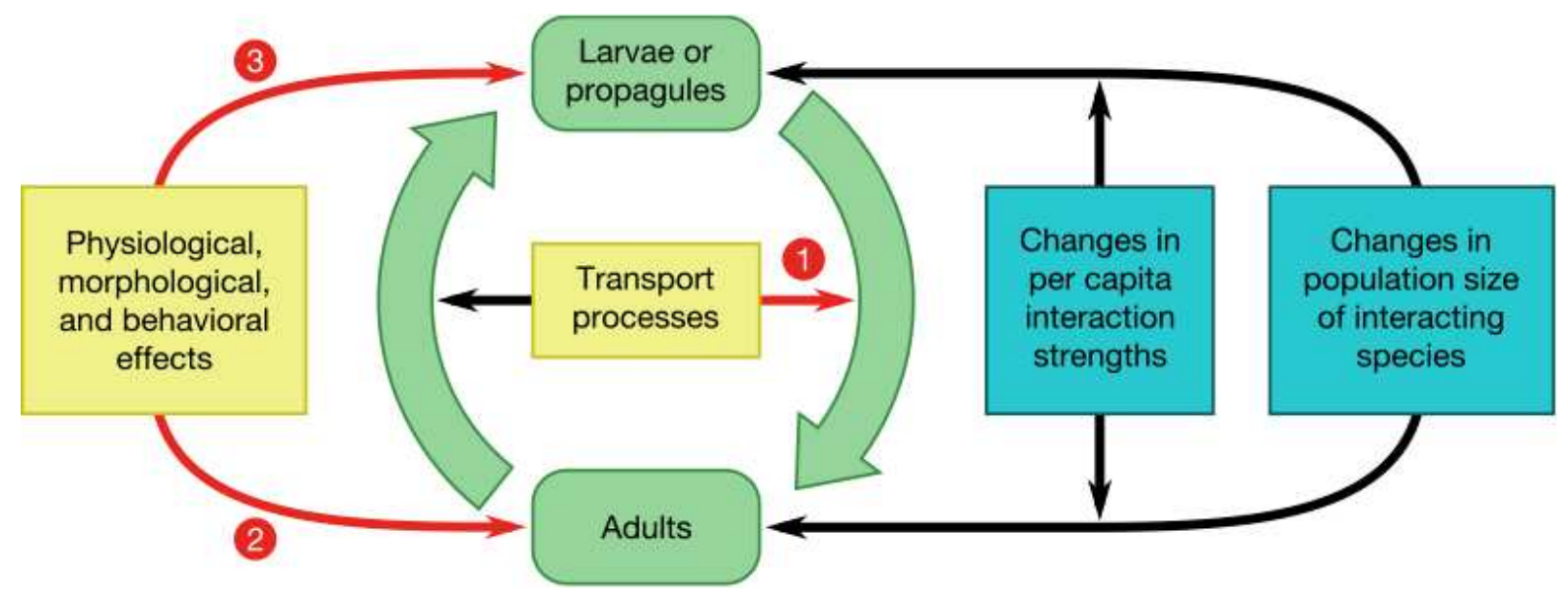

Figure 1 

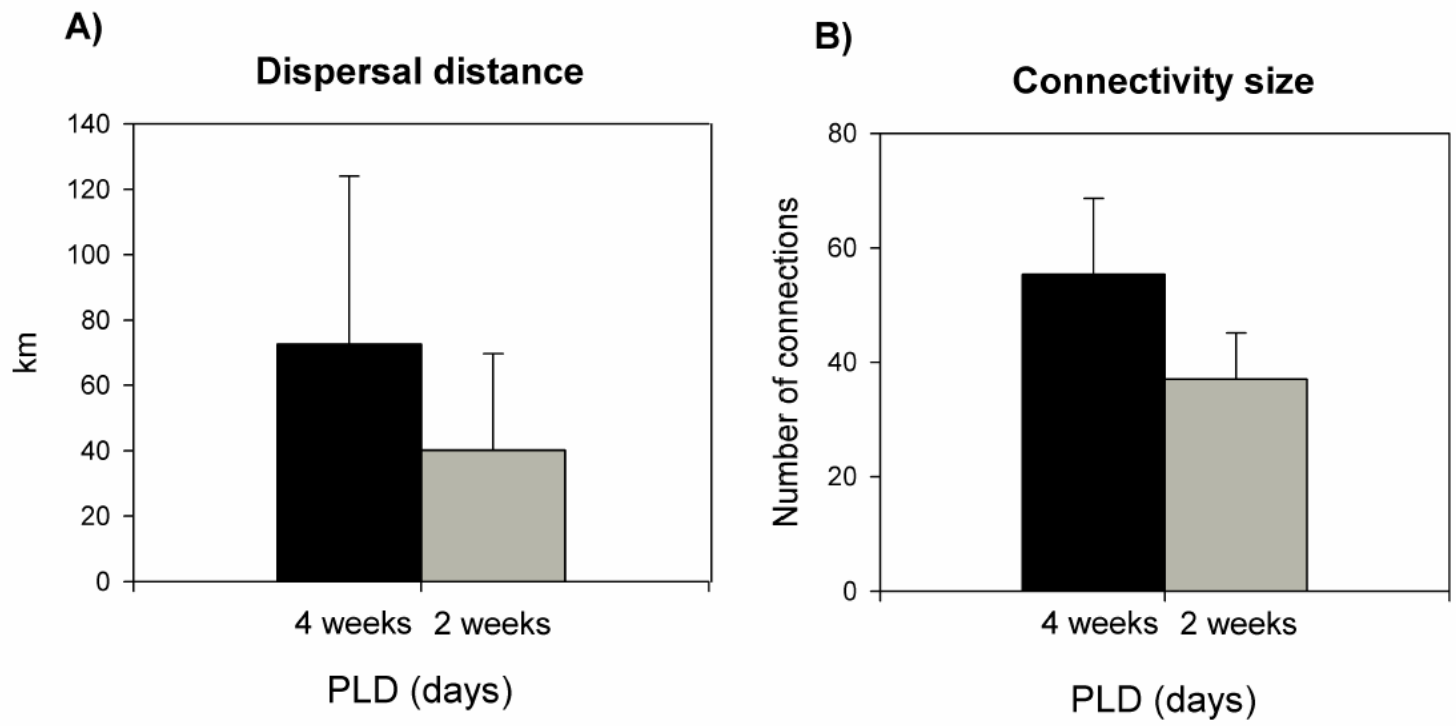

Figure 2 

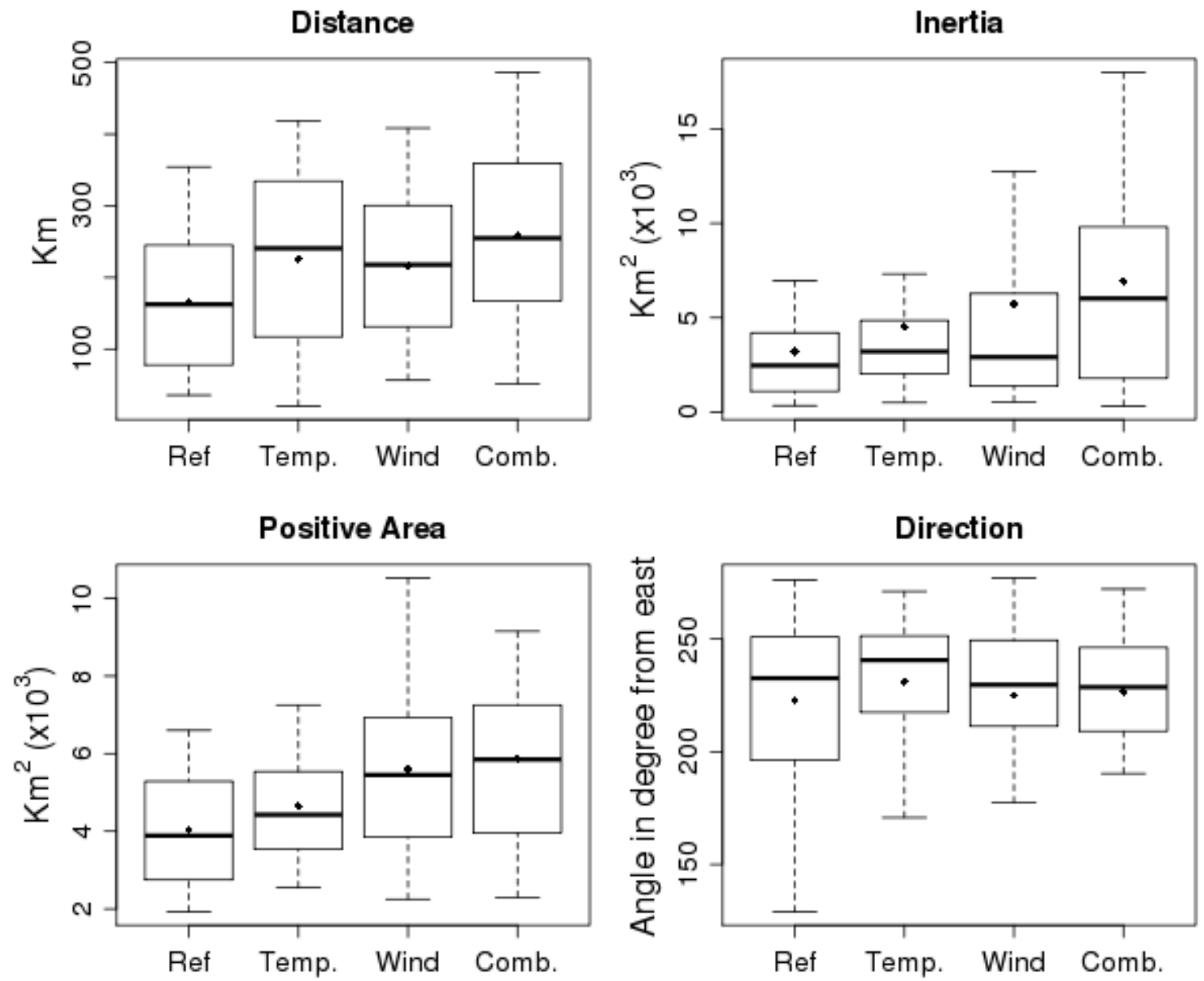

Figure 3 


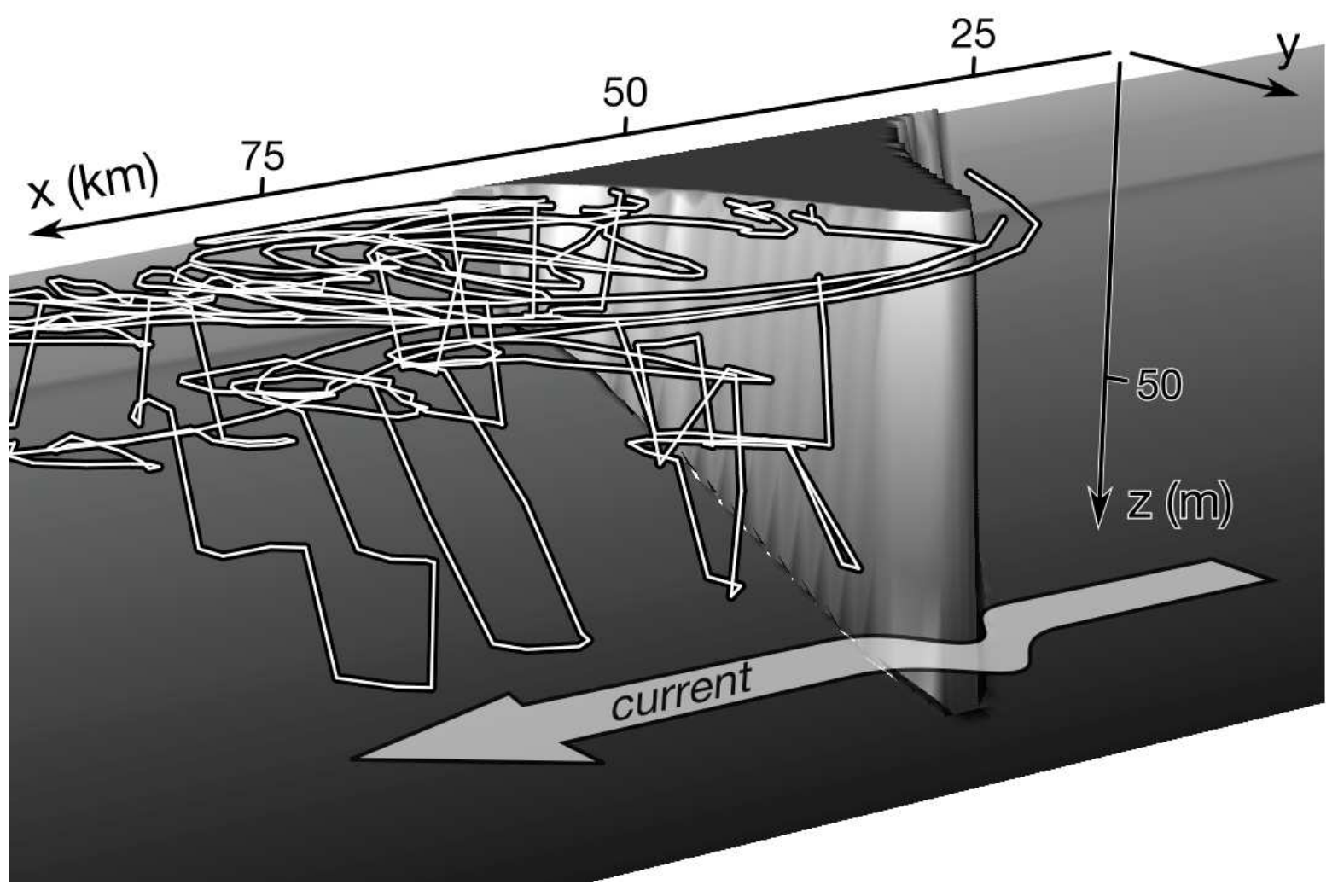

Figure 4 


\section{Table legends}

Table 1: Annual mean ( \pm SD, derived from spatially averaged values at each model time step) of the anomalies (scenarios 1, 2, or 3 relative to the reference run) of sea surface temperature and deficit of potential energy. The latter relates to the strength of the stratification.

Table 2: Relative increases in four descriptors of the dispersal kernel under the three 'what if' scenarios.

Table 3: Effects of a $2^{\circ} \mathrm{C}$ increase in sea temperature on the planktonic larval duration (PLD), percentage of self-recruiting trajectories, and recruitment rate in the island and promontory configurations. The reduction of PLD is computed after O'Connor et al. (2007). 


\section{Tables}

\begin{tabular}{|c|c|c|c|c|c|}
\hline \multirow{2}{*}{$\begin{array}{l}\text { 'What if' scenarios } \\
\text { 1. Air } \mathrm{T}+3^{\circ} \mathrm{C}\end{array}$} & \multicolumn{3}{|c|}{ Surface temperature $\left({ }^{\circ} \mathrm{C}\right)$} & \multicolumn{2}{|c|}{ Deficit of potential energy $\left(\mathrm{kg} \cdot \mathrm{m}^{-1} \cdot \mathrm{s}^{-2}\right)$} \\
\hline & 2001 & 2.18 & $( \pm 0.22)$ & 3.23 & $( \pm 1.87)$ \\
\hline & 2002 & 2.26 & $( \pm 0.21)$ & 2.85 & $( \pm 1.81)$ \\
\hline \multirow[t]{2}{*}{ 2. Wind $+30 \%$} & 2001 & -0.57 & $( \pm 0.38)$ & -11.3 & $( \pm 8.05)$ \\
\hline & 2002 & -0.59 & $( \pm 0.34)$ & -9.13 & $( \pm 6.81)$ \\
\hline \multirow[t]{2}{*}{ 3. Combined $\left(\mathrm{T}+3^{\circ} \mathrm{C}\right.$, Wind $\left.+30 \%\right)$} & 2001 & 2.15 & $( \pm 0.22)$ & -6.37 & $( \pm 5.65)$ \\
\hline & 2002 & 2.22 & $( \pm 0.20)$ & -4.64 & $( \pm 4.77)$ \\
\hline
\end{tabular}

Table 1 


\begin{tabular}{lcccc}
\hline 'What if' scenarios & Distance transported & Inertia & Positive area & Direction \\
\hline 1. Air $\mathrm{T}+3^{\circ} \mathrm{C}$ & $40 \%$ & $24 \%$ & $13 \%$ & $5 \%$ \\
2. Wind $+30 \%$ & $33 \%$ & $63 \%$ & $33 \%$ & $3 \%$ \\
3. Combined $\left(\mathrm{T}+3^{\circ} \mathrm{C}, \mathrm{Wind}+30 \%\right)$ & $58 \%$ & $70 \%$ & $3 \%$ \\
\hline
\end{tabular}

Table 2 


$\begin{array}{ll}\text { Configuration } & \text { Scenario } \\ \text { Island } & \text { Reference } \\ & +2^{\circ} \mathrm{C}\end{array}$

Promontory
Reference

$+2^{\circ} \mathrm{C}$
PLD (d) $\quad \%$ successful traject.

27

21.7

27

21.7
45

48

72

75
$\%$ successful indiv.

0.0092

0.028

0.015

0.044

Table 3 